\title{
STUDIES ON FACTORS INFLUENCING THE BEHAVIOR OF BOLTED FLANGED JOINTS
}

\author{
Revathy S J' ${ }^{1}$, Sonali Gyan ${ }^{2}$, Sneha Varghese ${ }^{3}$, Raju BS \\ ${ }^{1}$ currently pursuing masters degree program in Geomechanics and structures in Saintgits college, kottayam \\ PH-9496710771.revathysj@yahoo.co.in \\ ${ }^{2}$ currently working as scientist/Engineer in VSSC, Trivandrum.bs_raju@vssc.gov.in \\ ${ }^{3}$ currently working as scientist/Engineer in VSSC, Trivandrum.ersonali@gmail.com \\ ${ }^{4}$ Currently working as Assistant Professor in Civil Engineering in Saintgits College, Kottayam
}

\begin{abstract}
This article aims to study the parameters influencing the overall behavior of bolted flanged joints. Three dimensional finite element analysis has been extensively used to study the performance of bolted joints for eccentric tensile loading. Pretension in the bolt is modeled using ANSYS pretension element (PRETS179) which can be used on solid or line element types. Surface-tosurface contact elements are used to account for the contact pressure at various flange interfaces. The parameters considered for the study are bolt load, contact pressure between flanges and washers, flange opening and strains in the bolt. The effect of preload on various parameters is studied. This paper illustrates the behavior of bolted flanged joints in entirety and brings out the effect of prying action on the bolted flanged joint.
\end{abstract}

Index Terms-Bolt Load, Bolted joint, Contact Elements, Contact Pressure, External load, Pretension, Strains $* * *$

\section{INTRODUCTION}

Onnections form an important part of any structure and are designed more conservatively than members. This is because, connections are more complex than members to analyze, and the difference between analysis and actual behavior is large due to uncertainties. The connections in structures are of two types: (1) permanent \& (2) temporary. Welded joints are permanent joints while bolted joints are temporary joints. Bolts are commonly used mechanical attachment due to their simplicity and low cost. They are used in many different engineering applications, and can take on a wide variety of forms. Bolted joints are generally made up of the bolt head, stud, nut and the flange (top and bottom), as shown in fig. 1

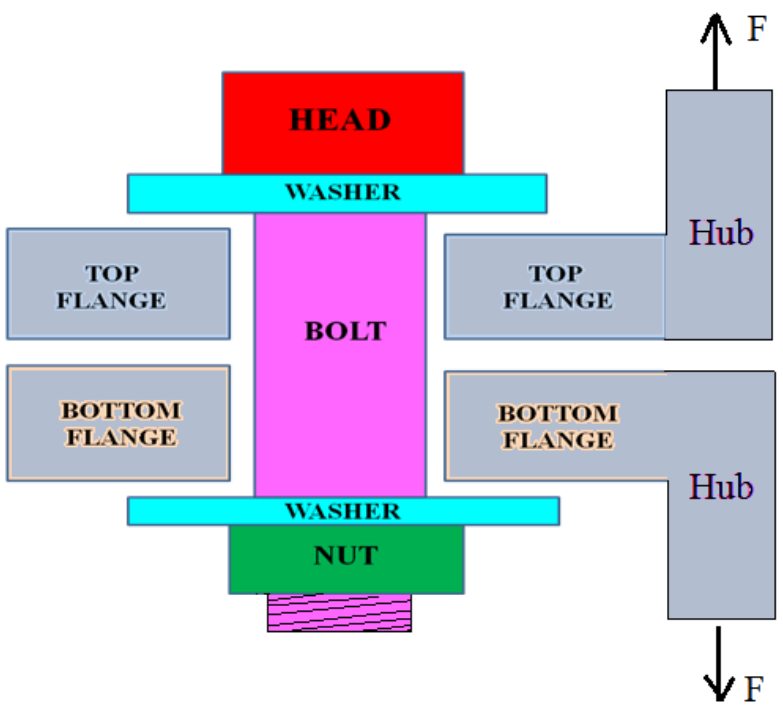

Fig.1: Schematic diagram of Bolted Joint
The joint separation becomes critical at tensile loading of flanged bolted joints. To minimize the joint separation, a pretension load is applied to the bolt known as bolt preload. The purpose of the bolt preload is to place the bolted member components in compression for better resistance to static or cyclic external loads and to create compression force between the parts or members so that the shear loads can be resisted by friction forces. In general, Preloading the bolts is done to

- Reduce cyclic stresses

- Maintain joint closure

- Increase overall stiffness.

- Reduce the bolt bending stress

In aerospace industry, bolted flanged joints are very common in both the pressurized and non pressurized structures. The interface joints of an interstage structure of any launch vehicle will be under threat for tensile loads. The reason is prying action. It is observed that flanged joint under tensile load will undergo more bolt tension due to eccentricity known as prying. This paper presents the behavior of the bolted joint under prying condition.

Several authors have suggested both theoretical and experimental methods to study the behavior of bolted joint. Patil et.al ${ }^{[1]}$ describes the behavior of bolted flange joint under tensile, torsional, bending external loads. Finite element analysis was used to study the deformation behavior and it also considers the stiffness values for each loading. The load factor can be positive or negative. The variation of negative load factor was included. Validation of existing model in bending was also done in this study. Grant M Henson et.al ${ }^{[2]}$, proposed an evaluation of common analysis methods of bolted joints in launch vehicles. Accurate calculation of bolt 
force in a bolted joint under external loads and temperature changes is a fundamental requirement. There are several methods for the analysis. They are approximate formulas idealizing mechanical models. They analyze an axisymmetrical thermal stress model with no external loads. The consistency of hand formulas and comparing it with FE results are studied. Three hand calculation methods are considered. Analysis of a bolted flange joint in which offset between the external load and the bolt creates prying effect is carried out. In this case, a prying factor is incorporated which simplify the hand formulas. Jeong.Kim et.al ${ }^{[3]}$, deals with finite element analysis and modeling of structure with bolted joint. In order to study the modeling techniques of bolt, four models are introduced: solid bolt model, coupled bolt model, spider bolt model, no bolt model. All the proposed models take into account of pretension effect and contact behavior between the flanges to be joined. Comparison is made between experimental test and modal test. Solid bolt, most accurately predict physical behavior of bolt. In the view of modeling easiness, Coupled Bolts are also used.

J.Wileman $^{[5]}$, studies the effect of member stiffness in bolted joint. Analysis of model was done using ANSYS. Analysis was done on different models with different materials and properties. The basic aim of the study was to obtain a simple solution to current design problem. It was obtained that non dimensional method was simpler. It was observed that current methods were overestimating the results. Marshall et.al ${ }^{[6]}$, describes the characterization of contact pressure distribution by experimental approach. Simple specimens consists of plate bolted to the base is used. Two specimens with different surface finishes were used. Ultrasonic scanning method was carried out for various torque values. Parallel calibration procedure was also implemented. For this paper, it was concluded that the surface roughness profile can lead to the significant changes in the spread of contact.

Norman.F.Knight et.al ${ }^{[7]}$, simulated structural response of a preloaded joint with two L shaped shell elements, modeled and it was connected by single bolt. Bolt stress was calculated from the basic theory of mechanics. All analysis was performed in ABAQUS/Standard. It involves two stages. From the analysis, effect on mesh, bolt preload, boundary conditions were studied. This analysis gave a guide to the modeling and its simulation .N. Tanlak et.al ${ }^{[8]}$, studied the response and failure behavior of bolted joint under impact loading . They developed a 3D model using solid elements. 12 - simplified finite models were produced and results regarding stresses and analysis time were obtained. It was concluded that simplified model 3: deformable shell bolt produces accurate results; complexity also reduces in this model.

\section{Nomenclature}

[1]. Cross sectional Area of Bolt $\left(\mathrm{mm}^{2}\right)$

[2]. Tensile stress Area of Bolt $\left(\mathrm{mm}^{2}\right)$

[3]. Percentage of Preload

[4]. Preload Force (N)

[5]. External load (N.)

[6]. Tensile Strength of Bolt $\left(\mathrm{N} / \mathrm{mm}^{2}\right.$
We observed that there are many analytical methods available to calculate the increase in bolt forces due to prying action. Other methods are through finite element analysis. It is depicted from literature that the accurate method of modeling a bolt is through solid brick elements. In this paper, finite element approach is used and ANSYS ${ }^{[10]}$, software is used to model and solve a three dimensional bolted flanged joint. SOLID185 element in ANSYS is used for the threedimensional modeling of bolted joint. The element is defined by eight nodes having three degrees of freedom at each node: translations in the nodal $\mathrm{x}, \mathrm{y}$, and $\mathrm{z}$ directions. The element has plasticity, stress stiffening, large deflection, and large strain capabilities. ${ }^{[9]}$

Bolt preload is simulated using PRETS179 element in ANSYS which can be used on solid or line element types. Surface-to-surface contact elements are used to account for varying contact distribution along flanges. PRETS179 has one translation degree of freedom and is used to define a 2-D or 3-D pretension section within a meshed structure.

The objective of this paper is to study the overall behavior of bolted flanged joints for an eccentric tensile loading through finite element analysis. In this work various parameters such as bolt force, flange opening, contact pressure for a defined preload is studied. Moreover, bolt preload is varied to observe its effects on the various parameters.

\section{PROBLEM STATEMENT}

Bolted flanged joint is shown in Fig 2. The dimensions are also provided in the figure.

Bolt of size M14 with following specifications is used.

$\begin{array}{lll}\text { - } & \text { Bolt Diameter } & =14 \mathrm{~mm} \\ \text { - } & \text { Bolt Length } & =27.5 \mathrm{~mm} \\ \text { - } & \text { Tensile stress area } & =125 \mathrm{~mm}^{2} \\ \text { - } & & \end{array}$

Initially the bolt is subjected to a preload of $60 \%$ of yield strength. The preload force can be calculated as;

$$
F=c * A_{t} * \sigma_{\mathrm{y}}
$$

Therefore the preload force is obtained as $77 \mathrm{kN}$. The external load which can be applied on the joint depends upon the maximum strength and permissible stress in the bolt.

$$
\begin{aligned}
& \sigma \quad: \text { Stress in the Bolt }\left(\mathrm{N} / \mathrm{mm}^{2}\right) \\
& \sigma_{1} \quad: \text { Major Principal Stress }(\mathrm{N} / \mathrm{mm} 2) \\
& \sigma_{2} \quad: \text { Intermediate Principal Stress }\left(\mathrm{N} / \mathrm{mm}^{2}\right) \\
& \sigma_{3} \quad: \text { Minor Principal stress }\left(\mathrm{N} / \mathrm{mm}^{2}\right) \\
& \text { Maximum Strength }=A_{t} * \sigma_{\mathrm{y}} \\
& \text { Permissible Stress, } \sigma=P / A
\end{aligned}
$$

The maximum strength is obtained as $128 \mathrm{kN}$. The joint is subjected to an external load of $20 \mathrm{kN}$. 

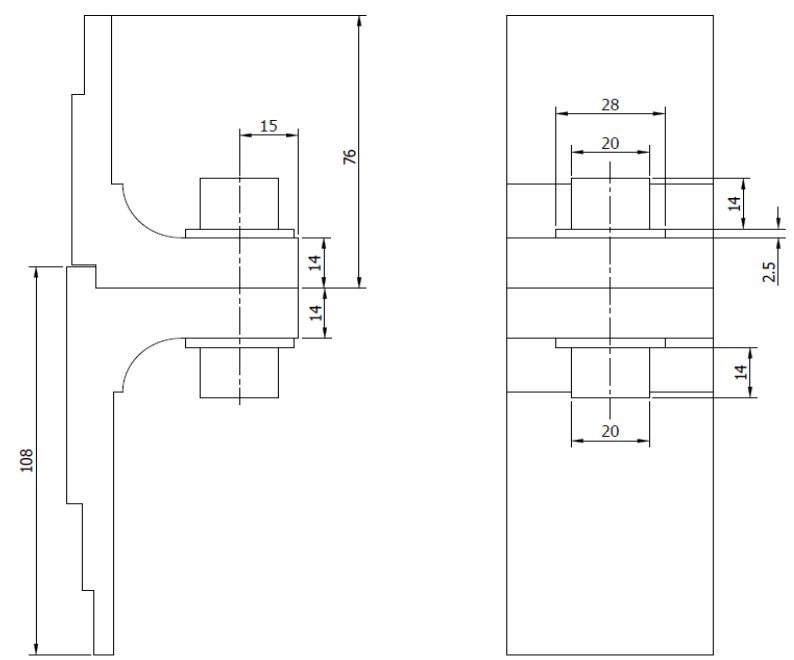

Table 1: Material Properties

Fig.2: Dimensions of bolt

\section{FINITE ELEMENT ANALYSIS}

\subsection{Finite Element Modeling}

The geometric model of the bolted flanged joint is carried out using CAD software and imported to ANSYS software for meshing. The solid geometric model is shown in Fig 3. The bolt and flanges are modeled using brick elements. Components of bolted flanged joint includes: upper and lower flanges, nut, upper and lower washers and bolt head. The solid bolt is the most realistic approach for simulation. It captures thermal, bending and tensile effects.

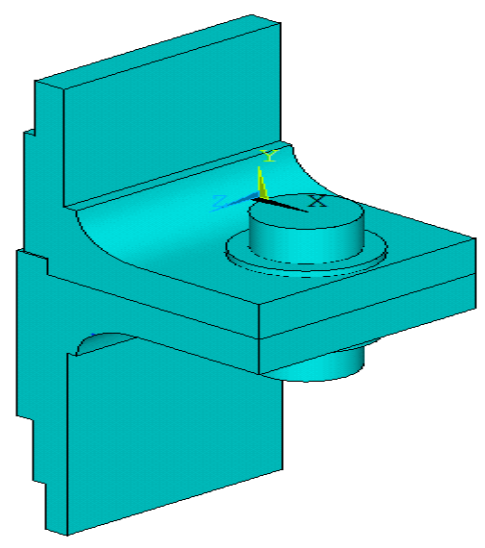

Fig.3: Solid Model

SOLID185 element in ANSYS for brick element and PRETS179 element for pretension is used.

Contact elements of type TARGET170 and CONTA174 are described in 5 locations and shown in Fig 4. These locations are:

- Bolt head to top washer

- Top washer to upper flange

- Upper flange to lower flange

- Lower flange to bottom washer

- $\quad$ Bottom washer to nut

The material of flange and bolt is aluminium and steel respectively. Table 1 shows the material properties.

\begin{tabular}{|l|l|l|}
\hline Material & Aluminium(Al) & Steel \\
\hline $\begin{array}{l}\text { Modulus of Elas- } \\
\text { ticity(E) } \\
(\mathrm{GPa})\end{array}$ & 68.6 & 210 \\
\hline Poisson's Ratio(v) & 0.3 & 0.3 \\
\hline Density $\left(\mathrm{kg} / \mathrm{m}^{3}\right)$ & 2800 & 7800 \\
\hline
\end{tabular}

Different mesh sizes are used. The smallest element size used is $3.31 \times 5.22 \mathrm{~mm}$. Total number of nodes is 11064 and total number of element is 11478 .
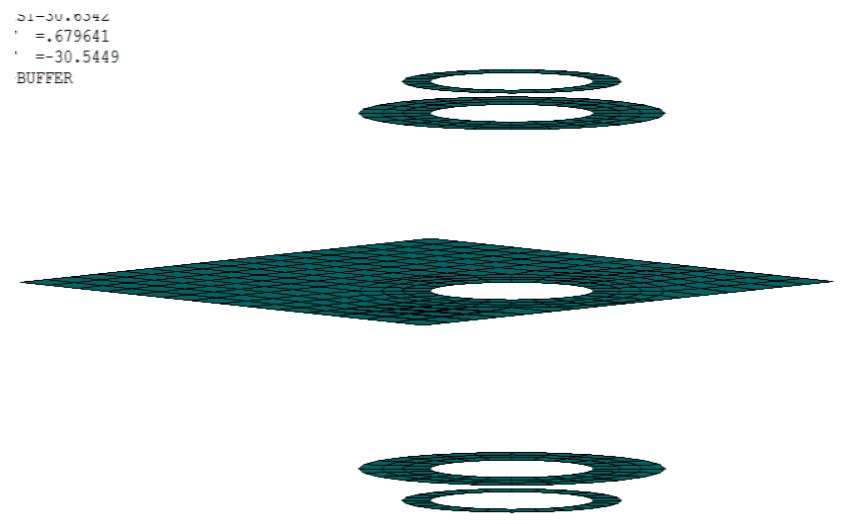

Fig.4: Contact Elements

The load must be applied to the joint in two load steps. First load step is to apply bolt pretension $(77 \mathrm{kN})$ and the second load step is to apply the external tensile load $(20 \mathrm{kN})$ incrementally.

Simply supported boundary conditions are applied over bottom portion of lower flange and symmetric boundary conditions at the side face of joint flanges. Load step 1 is shown in Fig 5 and load step 2 is shown in Fig 6.

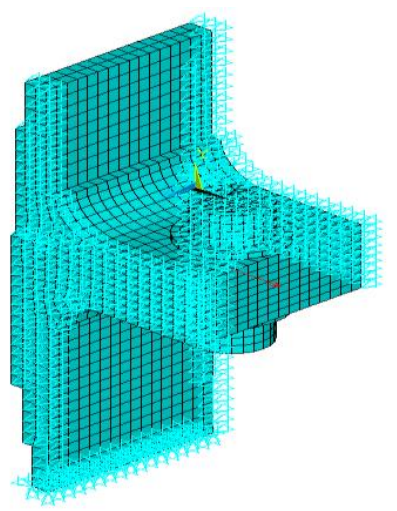

Fig.5: Load Step1 


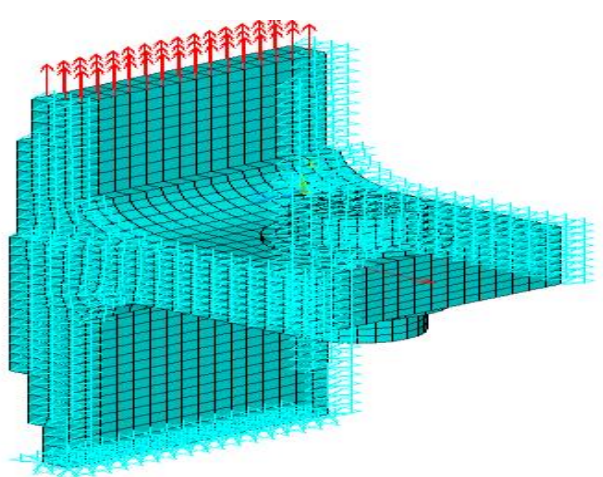

Fig.6: Load Step 2

\section{RESULTS AND DISCUSSIONS}

Nonlinear static analysis with contact is carried out to obtain displacement and stresses in the bolted flanged joint. Initially the joint is subjected to $60 \%$ preload i.e., $77 \mathrm{kN}$. Then, analysis of the joint is carried out for varying preload from $30 \%$ to $90 \%$. The deformed shape of the joint with load case 1 \& load case 2 is shown in Fig 6.

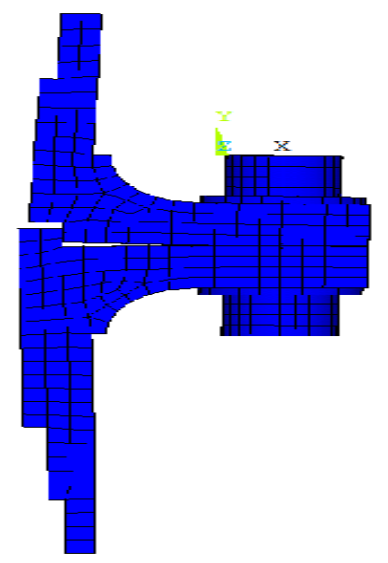

Fig.6: Deformed Shape

Table 2 provides the preload values varying from $30 \%$ to $90 \%$.

TABLE 2 Preload values

\begin{tabular}{|l|l|}
\hline $\begin{array}{l}\text { PRELOAD } \\
(\boldsymbol{\%})\end{array}$ & PRELOAD VALUE $\mathbf{( k N )}$ \\
\hline 30 & $1030 * 0.3 * 125=\mathbf{3 8 . 6}$ \\
\hline 40 & $1030 * 0.4 * 125=\mathbf{5 1 . 5}$ \\
\hline 50 & $1030 * 0.5 * 125=\mathbf{6 4 . 4}$ \\
\hline 60 & $1030 * 0.6 * 125=\mathbf{7 7 . 0}$ \\
\hline 70 & $1030 * 0.7 * 125=\mathbf{9 0 . 1}$ \\
\hline 80 & $1030 * 0.8 * 125=\mathbf{1 0 3 . 0}$ \\
\hline 90 & $1030 * 0.9 * 125=\mathbf{1 1 5 . 8}$ \\
\hline
\end{tabular}

Table 3 shows the axial displacement of joint at the inner side for the varying bolt preload. For $60 \%$ preload, the maximum axial displacement of the joint is $1.83 \mathrm{~mm}$. It is observed from Table 3 that the axial displacement of the joint decreases on increase of bolt preload. This is expected because as the bolt preload increases, clamping force on the flanges also increases resulting in lesser displacement of the flanges.
TABLE 3 Variation of Axial Displacement

\begin{tabular}{|l|l|}
\hline $\begin{array}{l}\text { PRELOAD } \\
\text { \% }\end{array}$ & ( \\
\hline 30 & 2.36 \\
\hline 40 & 2.30 \\
\hline 50 & 2.03 \\
\hline 60 & 1.83 \\
\hline 70 & 1.55 \\
\hline 80 & 1.42 \\
\hline 90 & 1.29 \\
\hline
\end{tabular}

\subsection{Variation of Bolt Load}

In this joint, at $60 \%$ bolt preload with external force varying from $0-20 \mathrm{kN}$ is studied. For a constant bolt preload, if external tensile force is increased then the force on bolt should also increase. Moreover due to eccentricity, an additional increase in bolt forces should be present. Table 4 shows the values for bolt load.

The variation of bolt force with varying external force is plotted in Fig 7. We can observe that as the external load increases, bolt force also increases as expected. From Fig 7, it is noticed that the change in the bolt force is minimal for the external load from $0-8 \mathrm{kN}$ and $0-14 \mathrm{kN}$ for bolt preload of $30 \%-60 \%$ and $70 \%-90 \%$ respectively. It is observed from Fig 7 that the rise in bolt force is steep as the bolt preload is varied from $30 \%$ to $60 \%$. Whereas, the rise in the bolt force does not change significantly as the bolt preload is varied from $70 \%$ to $90 \%$. This can be attributed to the nonlinear behavior of bolted flanged joints.

TABLE 4Bolt force at various external load for $60 \%$ prel-

\begin{tabular}{|c|c|}
\hline \multicolumn{2}{|c|}{ oad } \\
\hline EXTERNAL LOAD (kN) & BOLT LOAD $(\mathbf{k N})$ \\
\hline 0 & 77 \\
\hline 2 & 76.9 \\
\hline 4 & 76.8 \\
\hline 6 & 76.8 \\
\hline 8 & 76.9 \\
\hline 10 & 77.0 \\
\hline 12 & 77.3 \\
\hline 14 & 77.8 \\
\hline 16 & 79.0 \\
\hline 18 & 81.5 \\
\hline 20 & 84.4 \\
\hline
\end{tabular}




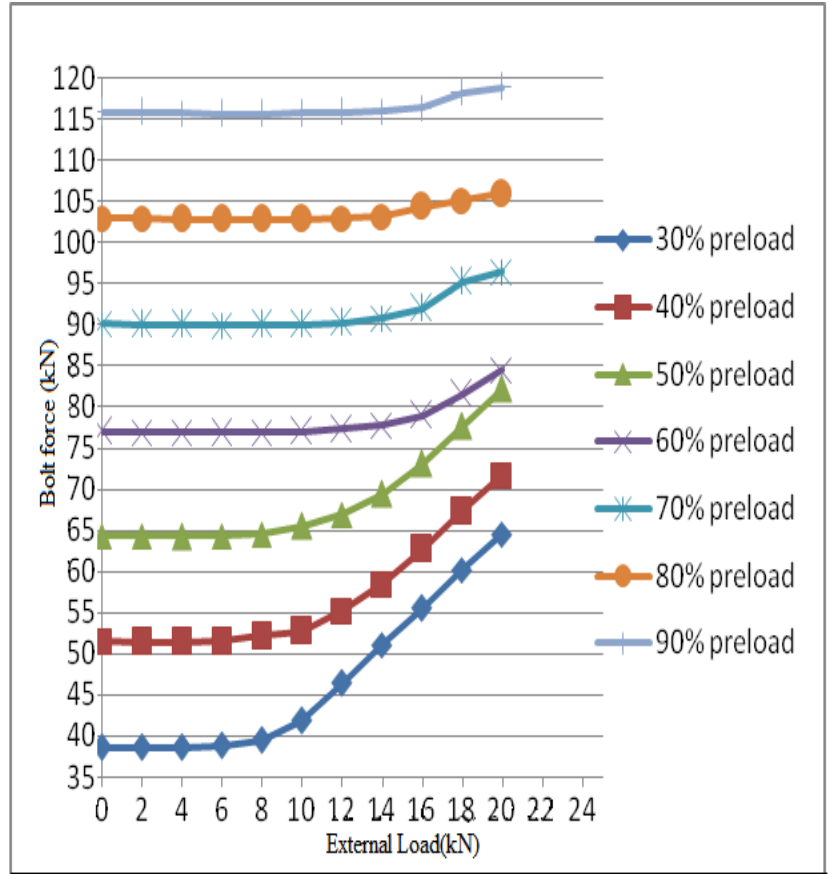

Fig. 7: External Load Vs Bolt Load with varying preload

\subsection{Variation of Flange Opening}

The primary objective of bolt preload is to hold the joint together and minimize the gap between the flanges. For a constant preload, on varying the external load the clamping force on the flanges decreases and the gap between the flanges increases. It is demonstrated in Table 5. The variation of flange opening is also shown in Fig 8.

From Fig 8, we observe that as bolt preload is increased from $30 \%$ to $90 \%$, for lower preload, the gradient of flange opening with the external load is high whereas for higher preload, this phenomenon is low. This is expected because at low preload the clamping force is also low and it causes the flange to open more as the external load increases.

\subsection{Variation of Contact Pressure}

Contact elements use a target and a contact surface to form a contact pair. Contact elements are provided at all the contact points of the model viz. bolt head to top washer, top washer to upper flange, upper to lower flange etc. Contact pressure values between washer and flange are provided in Table 6 . At $60 \%$ bolt preload with no external tensile load, the contact pressure is $386 \mathrm{MPa}$ whereas it increases up to $738 \mathrm{MPa}$ at $60 \%$ bolt preload and $20 \mathrm{kN}$ external tensile load. Generally with no eccentricity the bolt will face only tensile load. The bolt shank will face inner side tension and outer side less tension if eccentric loading is present. Here as the external load is increased for constant preload, the contact pressure should reduce but due to eccentric loading, compression is increasing.

TABLE 5 Flange opening at various external load for $60 \%$ preload

\begin{tabular}{|l|l|}
\hline EXTERNAL LOAD & FLANGE OPENING(mm) \\
\hline 0 & 0.07 \\
\hline 2 & 0.13 \\
\hline 4 & 0.19 \\
\hline 6 & 0.27 \\
\hline 8 & 0.37 \\
\hline 10 & 0.50 \\
\hline 12 & 0.66 \\
\hline 14 & 0.86 \\
\hline 16 & 1.11 \\
\hline 18 & 1.32 \\
\hline 20 & 1.52 \\
\hline & \\
\hline
\end{tabular}

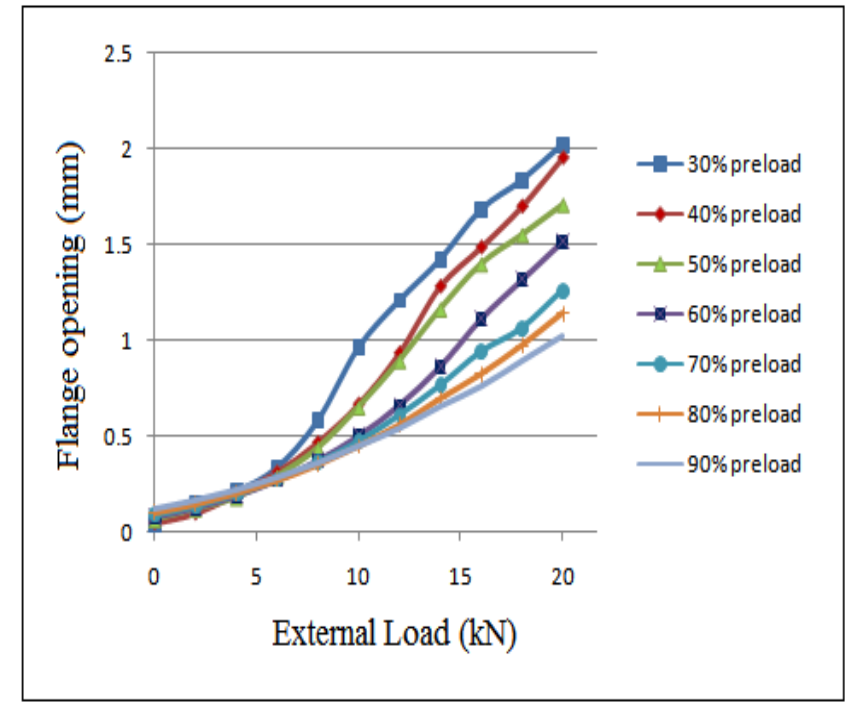

Fig.8: Variation of Flange opening with different preloads

\subsection{Variation of Strain}

The strain values are observed in the bolt shank at locations A and B. Location A and B is shown in Fig 9. At $60 \%$ preload, both location A and B are under tension but on application of external tensile eccentric load, a moment will cause tension of location A and compression at location B.

TABLE 6 Variation of Contact Pressure

\begin{tabular}{|l|l|}
\hline EXTERNAL LOAD $(\mathbf{k N})$ & $\begin{array}{l}\text { CONTACT } \\
\left(\mathbf{N} / \mathbf{m m}^{\mathbf{2}}\right)\end{array}$ \\
\hline 0 & 386.0 \\
\hline 2 & 385.9 \\
\hline 4 & 385.7 \\
\hline 6 & 385.8 \\
\hline 8 & 386.2 \\
\hline 10 & 387.1 \\
\hline 12 & 388.7 \\
\hline 14 & 391.7 \\
\hline 16 & 457.3 \\
\hline 18 & 598.4 \\
\hline 20 & 738.0 \\
\hline
\end{tabular}




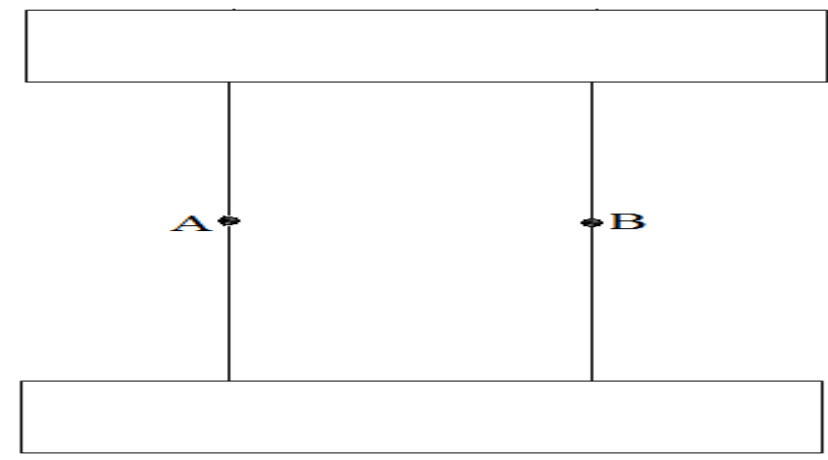

Fig.9: Location in bolt

Fig 10 show that as the external load is increased, location A is under more tension and the strain at this location is increasing. Similarly, as the external load is increased, location $\mathrm{B}$ is under compression and the cumulative effect of bolt preload and external load is to reduce

the strain at this location. This phenomenon is at constant bolt preload of $60 \%$. If bolt preload varies then the effect of external load on the strains at location A and location B also varies. Fig 11 shows the variation of strain at B by varying bolt preload. We observe that at

low bolt preload the fall in tension strain is more. At $30 \%$ bolt preload, the fall in tension is so much that it reaches to a state of compression. Bolt preload more than $40 \%$ allows location B under tension only. As the bolt preload increase, the fall in tensile strain is low.

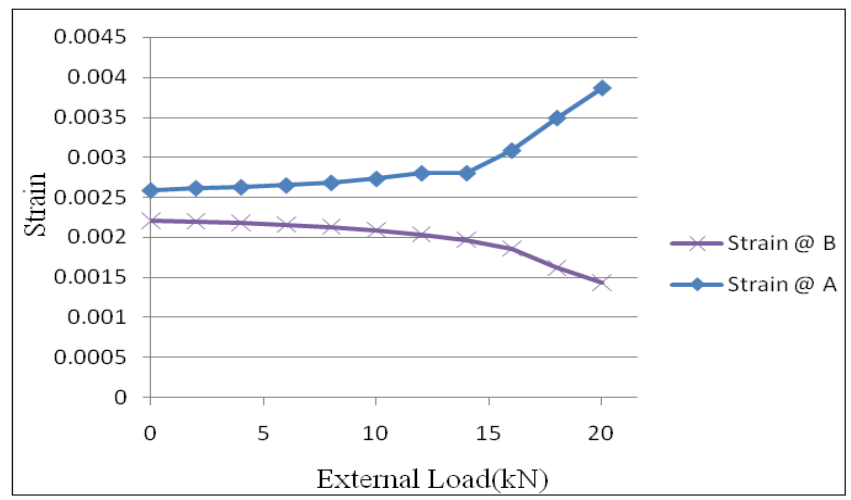

Fig.10: Variation of strain for $60 \%$ preload

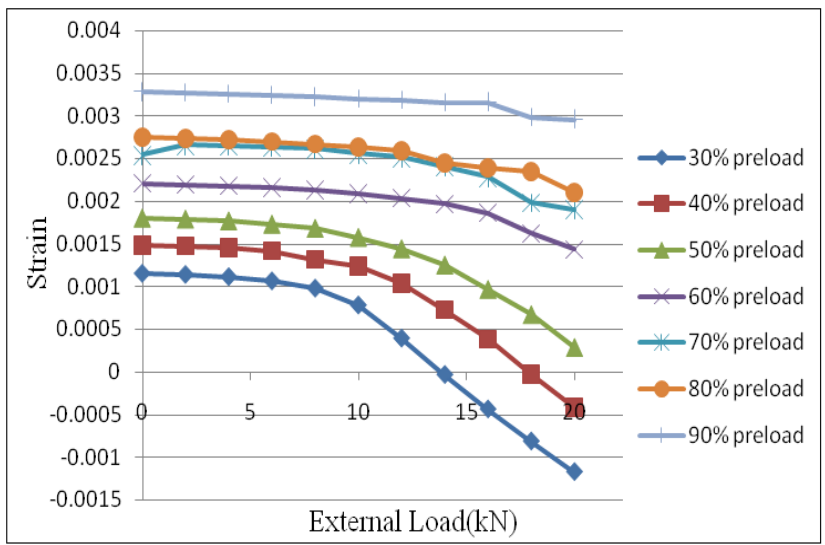

Fig11. : Variation of strain at B by varying preload The cumulative effect of bolt preload and external force on the bolt should be tensile strain only. If compression is pre- dominant then the bolt is bending and is not desirable. Hence an optimum value of bolt preload is expected. Normally $60 \%$ is the desirable bolt preload.

Similarly for location A, bolt strain with varying bolt preload $(30 \%$ -

$50 \%$ ) is plotted in Fig 12.

It is observed that as the bolt preload increases, the tensile strain also increases.

\section{CONCLUSION}

This paper deals with the study of various parameters influencing overall behavior of bolted flanged joints. The joint has been studied for $60 \%$ bolt preload and $20 \mathrm{kN}$ external tensile load applied eccentrically. For a constant bolt preload of $60 \%$, as the external force increases, bolt forces, contact pressure at the washer region and strain

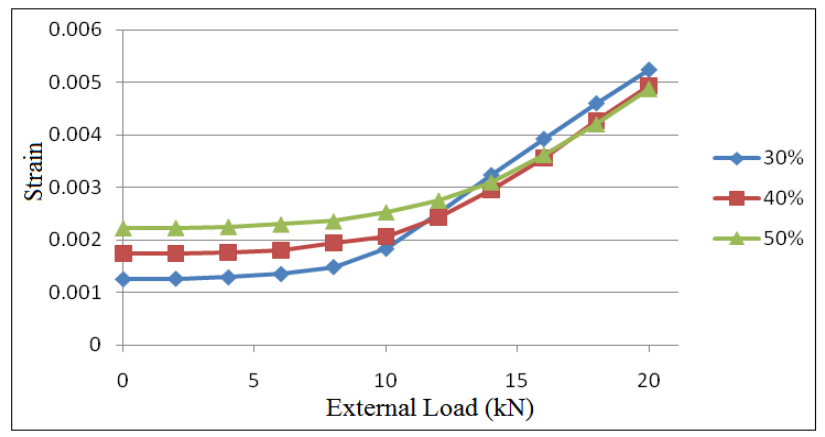

Fig 12: Variation of strain at location A from 30\%-50\% preload

in the bolt increase. This analysis has demonstrated the prying action also. In another study, as the bolt preload increases, bolt force increases and flange opening decreases.

From this study, it can be concluded that the most important parameter deciding the behavior of the bolted flanged joint is the bolt preload. It has been observed through studies that $60 \%$ bolt preload is required for the effective usage of the bolted joint.

\section{REFERENCES}

[1]. Dhiraj Kumar BalasahebPatil\& Rajesh RaosahebBorse , "Discussion of Behaviour for Bolt-Flange Joint", International journal of advanced Engineering, Research and Studies, Vol. IV, Issue.I, Dec 2014, 9698.

[2]. Grant M Henson \&Bryes A Hornish, "An Evaluation of Common Analysis Methods for Bolted Joints in Launch Vehicles", Structural Dyanamics and Material Conference, Vol.12, Issue 15, April 2010.

[3]. Jeong Kim, JooCheol Yoon \&BeomSoo Kang, "Finite element Analysis and modeling of structure with bolted joint", Applied Mathematical Modeling, Vol 31, Issue.5, May 2007, 895-911

[4]. Jerome Montgomery," Methods for Modeling Bolts in the Bolted Joint", Siemens Westinghouse Power Corporation, Orlando, FL.

[5]. J.Wileman, M.Choundhary\&I.Green, "Computation of Member stiffness in Bolted Joints", Journal of Mechanical Design, Vol.113, December 1991, 432-437. 
[6]. Marshall, M.B. Lewis \& Dwyer Joyce, "Characterisation of contact pressure Distribution in Bolted Joints", Strain, 42(1), 2006, 31-43.

[7]. Norman. F.Knight, Dawn R Philips \&IvaturySRaju, "Simulating Structural Response of a preloaded Bolted Joint", American Institute of Aeronautics and Astronautics.

[8]. N.Tanlak, F O Sonnez, E. Talay, "Detailed and Simplified models of bolted joint under impact loading", Journal of Strain Analysis for Engineering Design, Vol.46,Issue 3, April 2011, 213-225.

[9]. T.Fukuoka\&T.Takai, "Mechanical Behaviour of Bolted Joint in Various Clamping Configurations", ASME, Vol.120, Issue. 226, August 1998.

[10]. ANSYS 2013 Tutorial Manual. 